to, and that was the description of the author, in a line with a dozen other birders, wading through a long grass prairie in an attempt to flush a Baird's Sparrow. While this anecdote was properly set in a discussion of ethics (he stepped on a grouse nest) the action described was out of character with the rest of the book (or even the advice provided in the rest of the book) and the ethical dimensions could have been more forcefully argued. These points do not seriously detract from the book, and I would rank it among the best birding "howto" books I have encountered.
This book is aimed at the novice. If you have just started birding, this book is for you. If you know someone who has just started, this book would make a great gift. You may even want to lend it to your spouse, friends or relatives; anyone who is trying to figure out what all the fuss is about. Better still: donate it to the local school library after you are done with it. Will there be more to learn after you put this book down? Absolutely, but that is the whole point of the book: birding is a lifelong discovery.

MARK GAWN

1354 Viking Drive, Ottawa, Ontario K1V 7J6 Canada

\title{
BOTANY
}

\section{Alpine Plants of North America: An Encyclopaedia of Mountain Flowers from the Rockies to Alaska}

By Graham Nicholls and Rick Lupp, Consulting Editor. 2003. Timber Press, 133 SW 2nd Avenue, Ste. 450, Portland, Oregon 97204 USA. 344 pages. U.S. \$49.95. Cloth.

Entitled Alpine Plants of North America, this 344 page book takes an all-embracing look at many of nature's floral delights, which the author explains as being categorized as alpines, though they may be found anywhere from seaside to high mountain. Mr. Nicholls wins my applause by telling us that he likes to limit his plants to $30 \mathrm{~cm}$ (12 inches) in height, which I find keeps plants in scale in an average home rock garden.

The title might be a bit amusing to a Canadian - it appears to have been accomplished by excluding any plant references to land we hold dear! We are told the book is intended for practical, on site use, both in the field and in an owner's garden - generally Graham has succeeded but he falters a bit in the area of plant identification - something which is vital to enthusiastic alpine plant lovers. May I suggest that a few less species photographs and more emphasis on their clarity (there were a number of photos from which identification would be difficult if not impossible). More closeups of flowers and foliage would help a great deal.

I thought that the format of the book was excellent: information on plants' natural growing areas and cultural tips made for a most helpful package of useful information. Choosing the best location and growing medium for our newest acquisitions is very often a painful experience. Having several identical plants and plenty of spare sites is sometimes our best hope of

\section{Arboretum America, A Philosophy of the Forest}

By Diana Beresford-Kroeger. 2003. University of Michigan Press, 839 Greene Street, Ann Arbor, Michigan 481043209 USA. 196 pages. U.S. \$29.00.

Arboretum America, A Philosophy of the Forest is a unique work. It's a book about trees in a compound context - global, local and personal - informed by an success. However, a careful reading of the needs of each species covered in this book should save many early plant funerals!

The introduction of little known species is great fun and I applaud Mr. Nicholls's inclusion of Talimums in his writing. I have only one species in my collection to date $-T$. selinoides - but after seeing photos of such beauties as T. brevifolium, and T. 'Zoe', I shall be very soon searching for more. It is most amazing to observe the miniature size, quantity and length of blooming period in this enjoyable plant.

It is refreshing to find a proven plantsman willing to share his knowledge of plant propagation so freely. This is most evident in his detailed directions concerning the taking of cuttings from various species of Phlox. Perhaps his most helpful writings in this area are the descriptions of each species' natural surroundings, soil conditions, and moisture tolerance. The book entices the reader to find suppliers of seeds, plants, or best of all to follow in Graham Nicholls' footsteps - to see at first hand the alpine specimens he has so carefully covered.

Both author Graham Nicholls and consulting editor Rick Lupp have done a magnificent job in producing a book of much needed information about the identification and growing of alpines and done it in a neat, readable, and orderly fashion. This book will give the reader true value for his or her money.

WILLIAM BARKER

8 Stonecroft Terrace, Kanata, Ottawa, Ontario, K2K 2T9 Canada

intriguing variety of perspectives, including ecology, ethnobotany, horticulture, ethnology and mythology. The result is an eclectic and appealing book, no great surprise considering that the author, Canadian Diana Beresford-Kroeger, is, according to the back cover, a "botanist, medical and agricultural researcher, lecturer and self-defined "renegade scientist" in the fields of 